\section{POPPER POR DENNIS PARKER: O MANIFESTO QUE REVELOU A MÚSICA CONTIDA NO HIGH SCHOOL OF CELLO PLAYING}

\section{Teresa Cristina Rodrigues Silva}

RESENHA - PARKER, Dennis. The Popper Manifesto: A Doit-yourself Guide to David Popper's "High School of Cello Playing" (40 Etudes Op. 73). DVD + CD. Baton Rouge, LA: Dejapark Press, 2002.

Um cartaz escrito com letras garrafais e impresso em papel rústico, que poderia estar afixado nos postes pela cidade. Assim é a inusitada capa do DVD “The Popper Manifesto" - projeto realizado pelo violoncelista Dennis Parker que apresenta a extraordinária gravação dos 40 Estudos para violoncelo Op.73 de David Popper (1843 - 1913). O DVD vem acompanhado de um CD com arquivos de textos nos quais o próprio violoncelista discorre sobre diversos aspectos técnicos de cada estudo, intitulado The Popper Manifesto - A Do-it-Yorself Guide to David Popper's "High School of Cello Playing". Até o momento, esta é a única gravação completa da obra, divulgada em DVD. O projeto foi realizado em 2002 e a primeira tiragem dos textos foi realizada em papel. Posteriormente, passaram a ser distribuídos em CD.

Executar os prodigiosos 40 Estudos de Popper requer grande domínio da técnica do violoncelo. A obra se tornou uma fonte didática essencial de apoio para a execução do repertório do século XIX e vem sendo utilizada pelas escolas de música nos cinco continentes. Sua fama não chega às grandes salas de concerto como os Caprichos de Nicolò Paganini $(1782$ - 1840), mas podemos nos arriscar a dizer que o High School, de Popper, corresponde, em termos de evolução técnica ocorrida no século XIX, aos Capricci daquele gênio do violino.

Virtuosismo, versatilidade e muita desenvoltura marcam a carreira do violoncelista Dennis Parker. Este músico excepcio-
1. Instituto Federal da Paraíba (IFPB). Email: tecrisrs@uol.com.br. 
2. Todas as informaçôes sobre a biografia e discografia foram obtidas através do website do violoncelista: <www. dennisparkerland.com> nal nasceu nos Estados Unidos, apresenta-se frequentemente como solista, recitalista, regente, colaborador e professor convidado em muitos festivais e universidades em seu país e no exterior. Atualmente é Haymon Professor of Music na Louisiana State University, onde ministra aulas de violoncelo e música de câmara desde 1988. Anteriormente, foi o primeiro violoncelo na Orquestra Sinfônica de Porto Alegre, Brasil, e também membro da Detroit Symphony Orchestra.

Sua discografia se destaca pela originalidade e ineditismo do repertório. Lançados pelo selo Centaur, aparecem os títulos Cello Matters (Coisas de Violoncelo) e Uplifting Discoveries from a Generation Lost (Descobertas Reveladoras de uma Geração Perdida). O primeiro apresenta música de Liduíno Pitombeira, Daniel Schnyder, David Baker e Astor Piazzolla; o segundo, obras de compositores que pereceram no Holocausto: Erwin Schulhoff, Gideon Klein, Viktor Ullmann e Hans Krása. Gravou também o CD Stolen Sonatas (Sonatas Roubadas), que contém suas próprias transcriçôes das sonatas para violino de Claude Debussy e George Enesco e da Sonata para Flauta de Francis Poulenc. Pelo selo Ariel Ventures, gravou Hommage to Fiddlers, apresentando a Sonata para violoncelo e piano de Ivan Sokolov, o Piano Trio de Viktor Kalabis e os Duos para Violoncelo e Violino de Jan Vicar.

Em 2012, aparecem mais dois títulos: Mozart on Cello? - dedicado às suas próprias transcriçóes de duas obras de W. A. Mozart - o Concerto No. 5 em Lá Maior (originalmente escrito para violino e orquestra) e a Sinfonia Concertante em Mi bemol Maior para Violino e Violoncelo (originalmente para violino e viola). O outro CD apresenta a obra completa para violoncelo do compositor brasileiro Walter Burle Marx - Concerto para violoncelo e Orquestra, gravado com a LSU Symphony Orchestra, sob a regência de Carlos Riazuelo, além das peças Sambatango, gravada com a pianista Lina Morita e Casanova Fantasy Variations para três violoncelos ${ }^{2}$.

O Manifesto Popper revela os atributos deste músico desde a sua forma de apresentação: capa e título se destacam pela originalidade. O termo "manifesto" denota a necessidade de divulgar uma ideia ou convicção. Em sua introdução aos textos, Parker declara: 
No decorrer da minha vida musical, desenvolvi um respeito profundo pelo domínio irrefutável de David Popper sobre o "planeta violoncelo". Este manifesto serve como uma forma de exorcismo dos pensamentos que têm ocupado horas incontáveis de estudo assim como as horas em que não estou estudando. Mesmo existindo inúmeras maneiras de tocar o violoncelo, todos os violoncelistas exploram a mesma literatura e, para os estudantes de qualquer parte do globo, os estudos de Popper são um denominador comum. $\mathrm{O}$ volume tem algo a oferecer para qualquer um: cordas duplas, staccato, spiccato, legato, geografia do espelho, campos de tonalidades pouco exploradas etc. Passados cem anos desde que estes estudos foram escritos, o trabalho de Popper continua sendo universalmente usado e apreciado (PARKER, 2002, p. 1).

Este projeto arrojado expóe e estabelece um patamar para a execução destes 40 Estudos. Além disto, os textos apresentam suas convicçóes acerca do métier, da técnica e da maneira de praticar: "Minha missão nesta gravação integral é compartilhar ideias, oferecer soluçóes e proporcionar uma referência sobre como os Estudos de Popper podem ser abordados" (PARKER, 2002, p. 1).

Dentre as particularidades deste registro destaca-se, sobretudo, a informalidade da gravação. Ainda em sua introdução, o violoncelista relata que, para a realização do projeto, ele foi seu próprio cameraman - optou por um espaço simples, em sua própria sala de aulas na Universidade onde leciona e utilizou somente uma câmera digital. Este, que poderia ter sido um dado que talvez comprometesse a qualidade do trabalho, tornou-se uma mostra inquestionável da naturalidade do músico que resulta em uma magistral performance, mesmo em condiçóes de gravaçáo de tamanha simplicidade.

Assim como a gravação, o texto é apresentado de maneira bastante informal. Parker se dirige especificamente aos violoncelistas e, apesar de versar sobre temas técnicos da execução bastante profundos, o faz sempre de maneira objetiva, com um humor arguto e com metáforas que contribuem e facilitam para que a leitura, assim como o vídeo, seja também um deleite. Além de tudo, o texto traz ilustraçóes elaboradas por seu filho, Roland Parker, que então contava com dez anos de idade. As imagens captam, com a perspicácia peculiar de uma criança, as mais variadas sensaçóes físicas e emocionais 
3. Não foram encontradas informaçōes precisas sobre quem foi Bernhard Schmidt. que um violoncelista pode ter ao enveredar-se pelos Estudos de Popper.

O compositor David Popper nasceu em Praga em pleno período romântico. Demonstrou seu grande talento musical ao piano e ao violino desde os três anos de idade. Foi admitido no Conservatório de Praga aos doze anos onde estudou violoncelo com Julius Goltermann. Aos dezoito, tornou-se "músico de câmara virtuose" na Capela Real do Príncipe Hohenzollern em Löwenberg. Popper foi também o violoncelista principal da Ópera da Corte de Viena entre os anos de 1868 e 1873. Mais tarde assumiu a posição de professor da Academia Real de Música de Budapeste (1886). Nesta mesma época, fundou um quarteto de cordas que ficou conhecido como "Budapeste". Os membros deste conjunto com frequência se juntavam a J. Brahms para execuçáo de suas peças. Popper alcançou grande popularidade com suas peças de saláo para violoncelo e piano, muitas delas tendo sido transpostas para o violino. Dentre os alunos de Popper, destaca-se Adolf Schiffer, que foi professor de János Starker (CAMPBELL, 2001, p. 71). É notável observar que Dennis Parker foi aluno de Starker, vindo, portanto de uma sucessão musical quase que direta de David Popper.

O Op.73, intitulado originalmente Hochschule des Violoncellspiels, tornou-se também conhecido com seu título traduzido para o inglês: High School of Cello Playing. Foi publicado entre os anos de 1901 e 1905, sendo, portanto, o primeiro livro de Estudos do século XX. A primeira edição se deu em quatro volumes contendo dez estudos cada. $\mathrm{O}$ primeiro volume foi publicado em 1901 e dedicado a Alwin Schröder (1855-1928), violoncelista e pedagogo alemão que, assim como Popper, foi reconhecido em seu tempo como grande virtuose do violoncelo. O segundo e o terceiro volumes foram publicados em 1902 e dedicados a Bernhard Schmidt ${ }^{3}$ (1837-1917) e a Edouard Jacobs (1851-1925), violoncelista e pedagogo nascido na Bélgica. O quarto volume foi dedicado ao compositor Húngaro Ödön von Mihalovich (1842-1929).

Esteticamente, estes Estudos estão distantes do estilo cultivado por Popper em suas peças de saláo. Trata-se de composiçóes com harmonias mais complexas e foram inspirados 
pela música "culta" em voga no final do século XIX. Segundo So Youn Park:

[...] a motivação de Popper para criar tais estudos foi o seu contato frequente com a música de Richard Wagner (1813 - 1883). Como primeiro violoncelo da Ópera de Viena, ele lidou com o desafio de executar as elaboradas partes das óperas de Wagner. Portanto, ele teve que decidir por arcadas e dedilhados para as passagens difíceis e, com isso, construiu uma técnica para atender às demandas desta música moderna que incluía trechos um tanto virtuosísticos (PARK, 2007, p. 8).

Um indício desta afirmação é o Estudo No. 19 que ficou conhecido como "Lohengrin" devido à passagem semelhante que se encontra na parte de violoncelo do Terceiro Ato desta ópera de R. Wagner.

Dentre as características composicionais dos estudos destacam-se as longas frases, características das obras do estilo Romântico, a construção frequente de frases em sequências e, sobretudo, o cromatismo. Alguns estudos se apresentam mais técnicos ritmicamente e outros mais inspirados melodicamente.

\section{DESTAQUES}

Além do alto domínio técnico exigido por estes Estudos, é importante ressaltar que este tipo de produção é bastante incomum de se ouvir em gravaçôes. Não são obras destinadas às salas de concerto e geralmente ficam confinadas às salas de estudo e às salas de aula, mesmo que possuam qualidades musicais bastante apreciáveis. Eles exploram inúmeros aspectos da técnica do instrumento e, consequentemente, todos eles sem exceção, apresentam diferentes desafios para o violoncelista.

Os Estudos de No. 4 e 21 trabalham ostensivamente longas frases em longos legatos, cobrindo frequentemente a extensão das quatro cordas e exigindo grande sustentação e controle nas mudanças de arco assim como da coordenação dos movimentos da mão esquerda. Além disto, o de No. 4 demanda o emprego persistente do capotasto (posição de polegar para a mão esquerda) e está escrito em uma tonalidade não muito confortável ao instrumento: Fá\# Maior. Neste tom, o instrumentista náo consegue utilizar a ressonância natural do 
instrumento porque a tonalidade não privilegia os harmônicos naturais. No entanto, Dennis Parker interpreta esses dois belos Estudos com precisão e poesia.

Os Estudos 10, 21 e 23 possuem caráter mais lírico, são bastante cromáticos e estáo escritos em tons menores: Dó menor, Lá menor e Si menor, respectivamente. Observamos que o de No. 10 tem a indicação Appassionato e é construído com sequências descendentes de arpejos e escalas com dinâmicas entre ff e ppp. Nada melhor do que o texto do próprio violoncelista descrevendo tecnicamente este estudo: "O título Appassionato nos a fornece a dica de que as divisóes impetuosas e irregulares e a velocidade do arco devem ajudar a produzir essas ondas de som" (PARKER, 2002, p. 26).

Dentre os Estudos de caráter mais rítmicos, alegres ou jocosos destacam-se os de No. 5, 14, 18, 22, 28, 32, 36 e 40. Parker imprime admirável vivacidade e elegância nestes Estudos. Os Estudos 5 e 36 estão baseados no ritmo de giga, dança bastante cultivada no século XVIII. O No. 5, em Lá Maior, apresenta a giga francesa com a presença das notas pontuadas exatamente como aparece no Vivace do primeiro movimento da Sinfonia No. 7 de Beethoven. O No. 36 está baseado na giga italiana, em 3/8. O Estudo 14 explora principalmente as escalas descendentes em staccato volante - série de notas curtas executadas em uma mesma arcada. Este mesmo efeito é explorado também no Estudo 32. Já o Estudo 18, bastante vivaz, é um moto perpetuo construído inteiramente em semicolcheias e é um dos mais longos de todo o livro. Este Estudo está escrito em Ré Maior e explora os registros mais altos do violoncelo, incluindo também passagens de arpejos em harmônicos naturais. O Estudo No. 22 apresenta o tema principal composto sobre a escala pentatônica - sol, lá, si, ré, mi - conferindo-lhe um "ar" de música oriental. Intercalado aos motivos pentatônicos surge, invariavelmente, o cromatismo.

O Estudo 28 baseia-se em arpejos no registro alto do instrumento com emprego do capotasto e também com a eventual utilização do quarto dedo da máo esquerda. Popper, aparentemente toma emprestado o idioma da flauta para este Estudo tanto na condução dos arpejos quanto na escolha da tessitura. O Estudo 40 trabalha exclusivamente com harmôni- 
cos naturais, produzindo um timbre singular e cativante para o instrumento.

Outros Estudos que merecem destaque nesta gravação são os de no. 9, 13, 17 e 34. Estão são impressionantes pela facilidade com que são executados, apesar da alta demanda técnica. Os quatro trabalham ostensivamente a execução em cordas duplas. O de número 13 em especial, apresenta larga utilização dos intervalos de oitavas e terças. Na segunda metade deste, observamos longas passagens que associam cordas duplas com trinados na nota mais grave. A complexidade deste efeito nos remete indubitavelmente às passagens extravagantes do Capriccio No. 6 para violino solo de Paganini. O No. 17 é um estudo curto, porém, bastante exigente tecnicamente. Está escrito em Dó menor, na fórmula A-B-A, (Maior - Menor Maior) e explora o intervalo de sextas na seção A. Na seçáo B explora-se uma variedade maior de intervalos como terças, sextas, quintas e até mesmo décimas. Os Estudos de número 9 e 34 exploram principalmente os intervalos de terças e sextas. Neste último, o tema, de caráter popular, é construído sobre o ritmo de Siciliana, em 6/8, com eventuais acompanhamentos em pizzicati de mão esquerda.

A realização deste projeto mostra a afeição extraordinária de Dennis Parker em relação à atividade pedagógica que paira acima de qualquer suspeita de um simples exibicionismo de virtuosidade. É um projeto precioso que requer ampla experiência e reflexão para sua concretização. Trata-se de um registro singular que demonstra a grande maestria e, ao mesmo tempo, a magnanimidade deste músico. Em sua essência, o projeto é desprovido da expectativa de aclamação do grande público da música erudita. $\mathrm{O}$ resultado é um material de valor inestimável que deve obter, além da admiração e do reconhecimento, a gratidão de um grupo específico, formado basicamente por violoncelistas e admiradores deste instrumento.

O Popper Manifesto vem sendo divulgado em diversos países pelo próprio violoncelista, normalmente em master classes em Conservatórios, Universidades e Escolas de Música ${ }^{4}$.
4. A caixa contendo o DVD e o CD com os textos pode ser adquirida através dos websites: $<$ www.dennisparkerland. com>, <www.sharmusic. com> ou do email: info@ dennisparkerland.com. 


\section{REFERÊNCIAS BIBLIOGRÁFICAS}

CAMPBELL, Margaret. Nineteenth-century virtuosi. In: STOWELL, Robin (Ed.) The Cambridge Companion to the Cello. Cambrigde: Cambridge University Press, 2001. p. 6172.

PARK, So Youn. Effective Practice Methods for David Popper's Virtuosic Pieces and the Relationship Between Selected Pieces and Etudes. Tese (Doutorado em Música) - Florida State University, Tallahassee, 2007.

PARKER, Dennis. The Popper Manifesto: A Do-it-yourself Guide to David Popper's "High School of Cello Playing" (40 Etudes Op. 73). DVD + CD. Baton Rouge, LA: Dejapark Press, 2002.

POPPER, David. High School of Cello Playing: 40 Etudes for Cello Solo, Op. 73. New York: International Music Company, [s.d.]. 